\title{
RELACIONES SEXISTAS EN LA EDUCACIÓN
}

\author{
Sandra Araya Umaña
}

\author{
Recibido 8-I-2003 • Aceptado 11-III-2003
}

\begin{abstract}
Resumen: La igualdad formal de las mujeres tanto dentro del sistema educativo como fuera de él no significa la erradicación de las relaciones sexistas. La paridad entre los sexos en la matrícula escolar y el repunte de la presencia femenina en carreras técnicas no ha tenido un correlato en la transformación de los roles femeninos y masculinos. Es por eso que paridad y transformación genérica son dos aspectos que se ubican en dimensiones de diferente naturaleza, por cuanto la visibilización de las mujeres es una condición necesaria pero insuficiente para la creación de condiciones que posibiliten el surgimiento de nuevas expectativas, cambios de mentalidades y nuevas normas sociales.

Cuatro condiciones societarias prevalecientes en la sociedad costarricense y seis expresiones sexistas en la institución escolar constituyen una clara evidencia que aun falta un largo camino por recorrer. Sin embargo, el protagonismo docente a partir de su capacitación en los temas relacionados con el género puede ser la base a partir de la cual se inicien cambios en el sistema social y cultural. Es un proceso dialéctico: la institución escolar se transforma a partir de la resignificación de la práctica docente y, a la vez, su acción transformadora contribuye con la superación de las relaciones sexistas en la sociedad.
\end{abstract}

Palabras clave: Sexismo, Educación.

\section{Presentación}

En Costa Rica y en general en América Latina, los estudios sobre género y educación no son tan prolíferos como los de violencia, ciudadanía y derechos de las mujeres. A pesar de ello, es innegable la existencia de un rico material investigativo (Araya, 2001), que ha visibilizado las distintas formas en que opera el sexismo en la institución escolar.

Aunado a lo anterior, los foros mundiales sobre mujer, educación y derechos humanos, entre otros, y las denuncias de un decidido movimiento de mujeres han contribuido a la identificación de las distintas formas en que el proceso sociocultural genera un régimen de género (Connell, 1991) que diseña los destinos de las personas según sean mujeres $u$ hombres.

El reto actual, por tanto, no es QUÉ sino CÓMO superar las asimetrías existentes entre los sexos.

Los planteamientos posteriores pretenden ser una contribución a las respuestas del cómo. Para ello es preciso que en primera instancia hagamos un reconocimiento de las principales manifestaciones del sexismo en la institución escolar y en la sociedad en general. 


\section{Definiciones preliminares}

La discusión la debemos iniciar con una definición de lo qué es género por cuanto esta categoría constituye una veta teórica enriquecedora acerca de la construcción de los procesos socioculturales.

Como categoría analítica, el género refiere necesariamente al complejo mundo de lo social. Su uso destaca la interacción de un amplio espectro de instituciones económicas, sociales, políticas y religiosas como medio para la producción de los códigos culturales que guían el comportamiento de los hombres y de las mujeres.

En este sentido, se aleja de los determinismos biologistas ${ }^{1}$ que señalan los comportamientos diferenciados de mujeres y hombres como producto del sexo anatómico. "Los hombres son agresivos por las hormonas". "Las mujeres son lloronas por su propia naturaleza", son explicaciones que no encuentran cabida en el análisis de género debido a que más bien son atribuidas a la construcción cultural.

El género es el conjunto de ideas, representaciones, prácticas y prescripciones sociales que una cultura desarrolla desde la diferencia anatómica entre los sexos, para simbolizar y construir socialmente lo que es propio de los hombres (lo masculino) y lo que es propio de las mujeres (lo femenino) (Lamas, 1999, pág. 84).

El género apunta también a estudiar la relación entre mujeres y hombres como vínculos de dominación por medio del análisis de las prácticas y de las representaciones. Por ello no solo implica un compromiso teórico, sino también un compromiso político cuya consecuencia es la superación de las asimetrías entre los sexos (Mosconi, 1998).

En resumen, el género se puede definir como una herramienta teórica para el análisis de los fenómenos sociales y para la orientación de las estrategias metodológicas con un alto componente político.

A partir de lo anterior, la perspectiva de género supone una acción directa sobre la sociedad para cambiar los términos de las relaciones sociales -las que incluyen relaciones entre hombres y mujeres, entre mujeres y entre hombres- así como una voluntad política para cambiar los términos de las relaciones, de manera que sea posible la equidad, la igualdad y el empoderamiento ${ }^{2}$ de las mujeres (Lagarde, cfr. Guzmán, 1999).

Esta categoría ha sido de suma utilidad (Guzmán, op. cit.) pues:

- Permitió reconocer una diversidad de formas de interpretación, simbolización y organización de las diferencias sexuales en las relaciones sociales, creando las condiciones para una crítica a la existencia de una esencia o naturaleza femenina.

- $\quad$ Explicó la dicotomía que presenta a los sexos como opuestos, así como aquellas formas de comportamiento, representaciones y valoraciones que la cultura identifica como femeninas o masculinas, de acuerdo con la asignación de roles distintos asignados por cada sociedad a cada uno de los sexos.

- $\quad$ Evidenció que hombres y mujeres no son ni idénticos ni intercambiables y reconoce que las mujeres enfrentan mayores obstáculos para el ejercicio de la autonomía.

- Permitió comprender los estereotipos de género como creencias socialmente compartidas acerca de ciertas cualidades o rasgos que le son asignadas a las personas en razón de su sexo y que, en el caso de las mujeres, se han empleado para justificar un trato desigual y su subordinación.

- Explicó el impacto diferencial que tiene en las personas la experiencia de ser hombre o mujer en una determinada sociedad y en un momento histórico particular. 
Desde sus orígenes y hasta la actualidad han sido muchos los debates acerca del uso del género (De Barbieri, 1996, Guzmán, op. cit.), no obstante, el siglo XXI, irrumpe con el claro reconocimiento de su estatus como categoría analítica. Si bien el debate acerca de sus alcances conceptuales y políticos se ha acrecentado desde finales del siglo pasado -en especial en el mundo anglosajón (Hawkesworth, 1999; McKenna y Kessler, 1999; Connell, 1999; Smith, 1999; Scott, 1999; Lamas 1999)-, su uso cobra cada vez más fuerza debido a su carácter develador de las asimetrías entre los sexos y porque, como se anotó supra, constituye una forma de intervenir o actuar en la realidad con un claro compromiso para la superación de dichas asimetrías.

Es innegable que en los últimos tiempos han existido avances en la condición social de las mujeres. En el campo político -derecho a elegir y ser elegidas-, en el económico -derecho a heredar y a manejar su propio patrimonio, vinculación con trabajos remunerados en oficios reservados para hombres- y en el cultural -vestimentas, redistribución de tareas en el hogar, irrupción de mujeres en carreras universitarias tradicionalmente consideradas masculinas-.

Asimismo y según el Estado de la Nación (2001) hay indicadores muy halagüeños acerca de cambios experimentados en nuestro país en los últimos 10 años:

- $\quad$ En la educación formal, tanto la pública como la privada, existe paridad en la matrícula total del país. Es decir, 50\% de la población estudiantil son mujeres y la matrícula en el ámbito universitario comporta una participación femenina más alta que la de los hombres.

- La matrícula en los colegios técnicos también se ha equiparado. La presencia de las mujeres en carreras como computación se ha igualado a la de los hombres.

- La permanencia y aprobación de exámenes de $9^{\circ}$ y $11^{\circ}$ es mayor en las mujeres.

- La violencia doméstica se ha visibilizado y definido como un problema de salud pública.

- Hay interés estatal y comunal por desarrollar acciones de capacitación laboral y empresarial dirigidas a las mujeres.

En virtud de lo anterior, el término sexista podría parecer desconcertante o exagerado. No obstante, el hecho de que las mujeres accedan cada vez más a la igualdad formal, tanto en el sistema educativo como fuera de él, no supone que tengan las mismas oportunidades que los hombres, sino más bien que las formas de discriminación se tornan más sutiles y menos evidentes, persistiendo diversas manifestaciones del sexismo que es necesario desentrañar.

Manifestaciones sexistas son todas las formas, condiciones y acciones que en conjunto y en virtud del sexo de las personas, favorecen procesos que obstaculizan o impiden el desarrollo de cada una de las capacidades y potencialidades de los seres humanos.

El sexismo utiliza al sexo como criterio de atribución de capacidades, valoraciones y significados creados en la vida social, ordenando a la realidad con los cajones "esto es lo femenino" "esto es lo masculino". El sexismo es una forma de discriminación ya que, como otras discriminaciones es una práctica que tiende a encorsetar a las personas en parámetros impuestos (Morgade, 2001, pág. 11).

La diferenciación sexista afecta a las mujeres y a los hombres. Sin embargo, en el sexismo la diferencia se coloca en una 
escala jerárquica que termina por sostener el argumento que el diferente, en este caso las mujeres, son inferiores. Esta condición de inferioridad se perpetúa a partir de mecanismos - sutiles algunos y otros no tanto- que terminan por crear y consolidar representaciones sociales (RS) acerca de las mujeres y de los hombres, que a su vez actúan para transformar la diferenciación en segregación.

\section{Las expresiones societarias}

Prevalecen en nuestro país cuatro condiciones societarias que dan cuenta de la desventaja social y segregación de las mujeres, a saber:

\section{La posición subordinada en la economía}

Según el Estado de la Nación (op. cit.), la creciente participación de las mujeres en el mercado de trabajo no ha modificado la condición de subempleo visible que históricamente ha caracterizado su inserción laboral y que siempre ha sido más alto que en el caso de los hombres. De la misma manera, el desempleo abierto sigue presentándose en mayor escala en las mujeres.

La brecha salarial entre las mujeres y los hombres ha sido una constante $\mathrm{y}$, aunque experimentó una leve mejoría en la última década, se mantiene en casi todos los grupos ocupacionales y en todos los niveles de instrucción.

Asimismo ha habido un aumento en la categoría de trabajadoras por cuenta propia, pero en sectores de baja productividad en los que predomina la economía de subsistencia. Además de que los ingresos de estas mujeres son inferiores, la cobertura social de seguridad social es inexistente, en particular, en el régimen de invalidez, vejez y muerte, lo que aumenta sus condiciones de vulnerabilidad social.
La inserción laboral en estas condiciones favorece la pobreza de los hogares jefeados por mujeres y en especial de las mujeres jóvenes y de las zonas rurales.

\section{Las alternativas de campo de estudio y segregación ocupacional}

La equiparación en la matrícula estudiantil es sinónima de igualdad numérica; pero de ninguna manera ha significado una transformación del género.

La alta diferenciación ocupacional por sexo que prevalece en el país es reveladora de lo anterior, pues las mujeres siguen optando, en su mayoría, por actividades deficitariamente remuneradas.

Según un reciente estudio de Pilar Ramos (2002), los hombres dominan en las áreas de ingeniería, informática y seguridad, mientras que las mujeres predominan en la enseñanza y las ciencias sociales. Y, generalmente, se paga más a los hombres que a las mujeres aunque desempeñen el mismo trabajo.

De la misma forma, el repunte en la matrícula de la carrera de informática y electrónica ocurrido en los colegios técnicos no ha generado mejores condiciones salariales para las mujeres graduadas que, una vez colocadas laboralmente, reciben salarios inferiores que los hombres (Unión Europea, 1999). Esta situación, se produce porque las mujeres aceptan puestos en la manufactura más que en el nivel de diseño de estos campos, aunque dispongan de especialización para este último.

Por otra parte, los programas estatales que ofrecen becas de estudio, como el Fondo Nacional de Becas (FONABE), no subsidian las carreras de las áreas sociales, por lo que una proporción de mujeres de escasos recursos queda excluida de este tipo de beneficios.

La manera en cómo se eligen estas alternativas educativas y las subsecuentes opciones ocupacionales es producto de un 
conjunto acumulado y difuso de experiencias que las mujeres viven. Tales experiencias les trasmiten los principios y normas de la femineidad y la masculinidad. En esta transmisión la institución escolar cumple un papel preponderante, como veremos en líneas posteriores.

\section{El papel contradictorio de la familia y de las relaciones amatorias}

En Costa Rica, la valoración social de la familia goza de un lugar privilegiado. Aunque como madres, los mensajes sociales les atribuyen una alta consideración y respeto, como esposas y compañeras, las mujeres son víctimas constantes de la violencia doméstica.

Las estadísticas crecientes en el año 2000 (cfr. Estado de la Nación, op. cit.) en la línea gratuita Rompamos el Silencio del Instituto Nacional de las Mujeres (INAMU: 37000 consultas) y las denuncias en el Poder Judicial (32 643) revelan que un porcentaje significativo de los ofensores son hombres ${ }^{3}$.

Probablemente el aumento en el número de denuncias es producto de la Ley contra la Violencia Doméstica, en vigencia desde 1996. No obstante, las estadísticas no reflejan el problema en toda su dimensión ya que, por motivos de diversa índole, un sector de la población no denuncia este tipo de delitos. Estas cifras, por tanto, pese a su magnitud, son conservadoras.

El machismo prevaleciente en nuestra cultura es una de los detonantes de la violencia doméstica:

El machismo ha sido definido como la obsesión del varón con el predominio y virilidad. Ello se expresa en posesividad respecto a la propia mujer, especialmente en lo que respecta a los avances de otros varones y en actos de agresión y jactancia con respecto a otros hombres... Estructuralmente está inserto en un sistema patrilineal de parentesco y se apoya en un sistema legal que apoya el poder masculino dentro del hogar y en la división sexual del trabajo que restringe a la mujer a la esfera privada. El término fue usado originalmente para describir la representación de hombría del varón mexicano, pero ha pasado a ser juzgado como el complejo que caracteriza a los varones latinoamericanos (Fuller, 1998, pág. 258).

El machismo como práctica sexista abusiva coloca a las mujeres en situación de desventaja no solo en lo que respecta a la violencia doméstica, sino también en las relaciones amatorias, pues las mujeres y los hombres asumen y valoran el amor en forma diferenciada. Mientras que en el caso de los segundos, amar a las mujeres es solamente un elemento -entre otros- de realización posible; en el caso de las primeras, amar a los hombres es un fin en sí mismo (Lagarde, 1994). Esto provoca una tendencia en las mujeres a sentirse responsables de dicha relación, la cual se acrecienta cuando la relación no va bien, debido a la presunción de las mujeres de que ello ocurre por su culpa.

\section{Subrepresentación en los puestos políticos}

A pesar de que desde 1990 está vigente la Ley de Promoción de Igualdad Social de la Mujer que establece la obligatoriedad de nombrar un porcentaje significativo de mujeres en los cargos políticos, la representación femenina en dichos cargos no alcanza niveles satisfactorios.

Según un estudio del INAMU (2002), en la actual administración hay 7 ministras de 21 plazas existentes; solo en 26 de los 81 cantones existentes hay presidenta municipal y en las juntas directivas de 27 dependencias públicas, de 197 cargos disponibles 50 corresponden a mujeres.

El estudio reveló que hay órganos directivos constituidos únicamente por hombres o que incluyen solo a una mujer. Es decir, en lo que respecta a la toma de decisiones no solo no ha habido transformación genérica, sino que siquiera se llega a la paridad numérica. 


\section{La institución escolar}

Como fenómeno social, la educación tiene una dimensión social y política que complejiza los hechos y las relaciones educativas, pues es imposible separarla del contexto social e histórico en el que se inserta. De esta manera, la escuela como institución configurada para desarrollar el proceso de socialización incorpora las pautas, los significados y los símbolos culturales referentes a la discriminación de las mujeres en virtud de su sexo, por lo que trasmite y consolida de forma explícita a veces y latente las más, la ideología sexista prevaleciente en la cultura (González, 1987).

La estructura en cuanto a las jerarquías y distribución de puestos de dirección y decisión ya es reveladora de las relaciones asimétricas entre las mujeres y los hombres ${ }^{4}$ en la institución escolar. De la misma manera existen, según mi criterio, seis expresiones reveladoras del sexismo educativo:

- Los libros de texto. Este ha sido uno de los temas más estudiados, no solo en Costa Rica, sino también en América Latina (Araya, op. cit.). No obstante, a pesar de los esfuerzos de los organismos nacionales e internacionales, las imágenes y los mensajes que presentan los libros de texto continúan cargados de discriminación y no solo de género, sino también de otras exclusiones notorias. Las diversidades sociales, étnicas, religiosas, de edad o de incapacidad física o intelectual tampoco existen en los libros. En nuestro país se han dado algunos cambios como la eliminación en la enseñanza pública del texto Paco y Lola pero, la modificación de los textos escolares exige esfuerzos y trabajos sistemáticos que requieren la participación no solo de especialistas sino también de las casas editoriales y de las planificadoras y los planificadores educativos. Y es esta la tarea que, a pesar de los esfuerzos y buenas intenciones, continúa pendiente.

- El carácter androcéntrico del lenguaje. Dicho carácter es evidente no solo en los textos escolares sino también en el que es utilizado en la vida cotidiana escolar, pues hay una notoria ausencia de nominar a las niñas, maestras y madres de familia. Expresiones como: ¡Buenos días, niños"! "Nosotros los maestros", cuando el $100 \%$ son mujeres, son solo una muestra de como el lenguaje continúa invisibilizando a las mujeres.

- El abordaje de las ciencias sociales. Una de las manifestaciones más impactantes del sexismo en la educación son los contenidos de las ciencias sociales que se han enseñado tradicionalmente. La forma en que se reconstruyen las fiestas patrias, los movimientos de liberación y la historia de la construcción de la nación, en general, dan la idea de que los héroes son solo hombres. La ausencia y poca valoración a ciertas figuras y personalidades históricas femeninas, que al igual que muchos hombres lucharon y construyeron las libertades y derechos en el país (Pancha Carrasco, por ejemplo), refuerza la visión de que el mundo público, el mundo de las cosas importantes está protagonizado por hombres.

- La jerarquía de los saberes: Las ciencias naturales y exactas, la matemática y la tecnología son las que en la actualidad ocupan un lugar privilegiado en la planificación educativa. Estas áreas suelen ser asociadas a "ciencias duras", asimilándolas a lo masculino mientras que la expresión artística o literaria está asociada a lo suave y, con ello, a lo femenino. Las 
personas reconstruyen la realidad a partir de los cajones de lo femenino y lo masculino y, en la mayoría de las ocasiones, esto es imperceptible para ellas puesto que lo ven como natural, como lo socialmente aceptado. Y es precisamente esto último lo que nos lleva a la quinta expresión del sexismo escolar, pues el profesorado tiende a segregar al estudiantado en función de diferencias atribuidas a particularidades individuales o "naturales". Lo grave es que los diferentes roles que los hombres y las mujeres cumplen socialmente se confirman, cuando la población estudiantil está en la primaria y en la secundaria, por lo que la desvalorización de lo femenino cobra peso en estas épocas.

- $\quad$ El currículo escolar. El currículo no es solo que se dice o se hace, sino que también se trasmiten mensajes acerca de aquello de lo que no se habla. El funcionamiento del cuerpo, la expresión y valoración de los sentimientos, la dinámica del poder, entre otros, no forman parten del "qué" en la vida escolar y cuando aparecen generalmente son tratados de una manera superficial y burocrática, sin hacer mención de los dilemas personales y morales que muchas veces implican (Morgade, op. cit.). Aun cuando existe un sector de docentes que pueda estar tratando estos temas, existe un silencio sistemático de la escuela ante la sexualidad, el acoso sexual y la violencia intrafamiliar, entre otros, lo cual conlleva a la manutención de mitos que a su vez perpetúan los comportamientos aprendidos.

¿Cuánto se habla en las escuelas de la violencia familiar y de los mecanismos institucionales y legales para enfrentarla? ¿Cuántas veces escuchan los alumnos varones una frase contundente "No se le debe pegar a las mujeres ni a nadie”? ¿Cuántas veces escucharon las chicas, por ejemplo, "No es tu culpa si tu padrastro te asedia sexualmente y además puedes hacer algo para defenderte"? ¿Qué apoyo institucional y capacitación tienen las maestras y los maestros sensibles frente a estas cuestiones, para no lanzarse solas/os a tratarlas? (Morgade, op. cit., pág. 73.)

\section{Las alternativas y las estrategias}

¿Cómo hacer, entonces, para que la educación no solo supere los rasgos sexistas, sino que dialécticamente, en la medida en que se transforma a sí misma, transforme en su conjunto a la sociedad?

El sector educativo no es el único responsable de la socialización genérica. La institución de la familia juega un papel preponderante al respecto. Sin embargo, es sabido que todo cambio en un punto del sistema social repercutirá en los otros, por lo que este punto bien podría ser el proceso educativo.

De esta forma, incorporar cambios progresivos, pero sostenidos en el sistema educativo, indudablemente creará las condiciones para favorecer la transformación de las relaciones de género en los otros puntos del sistema social.

No obstante, vale advertir tres premisas:

La primera refiere a que el reconocimiento de la manutención y reproducción de prácticas sexistas en el ámbito escolar, nos debe orientar acerca del conocimiento de aspectos clave que debemos cambiar, pero ello no significa que debamos partir de clichés para la interpretación de dichas prácticas.

Debemos alejarnos de las interpretaciones que mapean a la institución escolar como una institución "maquiavélica" al servicio de la reproducción mecánica del sexismo y en su lugar visualizarla como una agencia socializadora compleja y dinámica en la que conviven en tensión, representaciones de género diversas (Bonder, 2001).

A partir de lo anterior se deriva la segunda premisa: Quienes participan en el proceso educativo no son tabla rasa como 
afirmaban las teorías de socialización de los roles. Están atravesados y atravesadas por un repertorio de discursos de género, con diferente poder normativo y prescriptivo que les ofrecen distintas formas de percibirse, percibir a la otra y al otro y actuar desde diversas posiciones genéricas. Las personas están interpeladas, además por discursos sociales de clase, etnia, de subcultura, que pueden articularse de manera más o menos fragmentaria y dinámica con las representaciones de género. Por tanto, tampoco se debe homogenizar a quienes están insertos e insertas en el sistema educativo.

Y la última es acerca también de las personas. El profesorado y el estudiantado son sectores que poseen la condición de agencia, es decir, que aunque están condicionadas socialmente, las personas son parte activa en su propia autodefinición y determinación y por ende pueden resignificar las prácticas educativas con un contenido altamente vindicativo de las demandas provenientes del género.

Así puntualizadas, mi propuesta para la búsqueda de opciones al cómo, apunta a la capacitación docente tanto en la formación inicial como en la continua, pues no basta con cambiar los libros de texto ni realizar modificaciones a los currículos si no existe la sensibilización y la disposición del profesorado para la superación de las relaciones sexistas en la educación.

No es un secreto el poder que dentro del aula tiene el profesorado. Por ello, la práctica educativa es una forma de poder, una fuerza social que puede actuar a favor del cambio o de la continuidad social (Carr, 1996). De ahí la importancia de la capacitación y el intercambio de conocimientos con el sector docente.

El planteamiento de la capacitación exige dar respuesta a tres grandes interrogantes a las cuales, sin ánimo de ser exhaustiva y agotar toda las posibilidades, pretendo dar respuesta:
- ¿QQuién capacita a quién?

- ¿En qué se capacita

- ¿Cómo se capacita?

\section{¿Quién capacita a quién?}

Los espacios universitarios como el Instituto de Estudios de la Mujer de la Universidad Nacional (IEM) y Centro de Investigaciones en Estudios de la Mujer (CIEM) de la Universidad de Costa Rica constituyen una opción de entes capacitadores. También lo son las ONGs que abordan, no solo desde la investigación sino desde la intervención, el tema de mujeres y que con su accionar han alcanzado una maduración política. Asimismo las oficinas de la mujer o programas de género surgidos en los gremios docentes ${ }^{5}$. Podría ser una de estas instancias la que asuma la conducción del proceso de la capacitación docente 0 , bien, las tres definiendo previamente líneas de coordinación entre ellas.

\section{¿En qué se capacita?}

La capacitación a partir del enfoque de género es, según mi criterio, la opción más acertada, pues dicho enfoque es el que ha permitido abordar de una manera diferente las relaciones sociales, evidenciando la desigualdad social de las mujeres.

Pero, no se trata de capacitar en las relaciones genéricas y en la discriminación, como si fuese la capacitación de un paquete informático, menos aún, si se toma en cuenta que la docencia está considerada como el núcleo duro (Morgade, op. cit.) del régimen de género y por tanto una de las menos anuentes a la incorporación de este enfoque.

Se debe tomar en cuenta que la inclusión de la teoría del género implica una doble perspectiva: hacia la práctica docente y hacia la propia identidad social. Es por ello que las respuestas ante los programas de 
género pueden ser de diferente orden: defensivas, cautelosas, temerosas, devaluadoras y también positivas y comprometidas.

En el sector docente existe una fuerte tendencia a considerar el género como un asunto solo de mujeres y dentro del mismo hay quienes consideran que es cosa de mujeres resentidas contrarias a los hombres. Lo anteponen además al concepto de familia y el género se recrea como el destructor de la armonía y la estabilidad familiar y social (Araya, op. cit).

En el sector educativo y, sospecho que también fuera de él, la drogadicción, la delincuencia y la deambulación de niños, niñas y adolescentes es atribuido a la inserción laboral de las mujeres y al abandono por parte de ellas de algunas de sus inherentes funciones -cuido de infantes, por ejemplo-.

Se dice también que la trasgresión de las pautas tradicionales en cuanto a las conductas permitidas y prohibidas para las mujeres y los hombres, podría desembocar en la creación de condiciones que favorecen el homosexualismo, lo cual es considerado un riesgo debido a la homofobia característica del medio costarricense.

En síntesis, la desconfianza y el rechazo hacia este enfoque son producidas, en buena parte, por las distorsiones del contenido y las propuestas que se derivan de los planteamientos de la perspectiva de género y por la homofobia.

Aunque estas expresiones podrían ser producto de pactos sexistas, es necesario su atento reconocimiento para así propiciar la difusión y comprensión de las desigualdades entre las mujeres y los hombres.

En cuanto a la promoción de cambios en el sector educativo, se debe considerar que las nuevas representaciones acerca de las relaciones sociales que estamos promoviendo no solo tocan cuestiones vinculadas con el conocimiento y el poder, sino también con los afectos, los deseos y los vínculos (Bonder, op. cit.) y por tanto generan una significativa movilización personal.
Es necesario, por ende, que quienes capaciten acerca del género, la discriminación y las relaciones sexistas, tengan una mirada cuidadosa para distinguir qué cuestiones específicas influyen en las actitudes y reacciones de las personas para no caer en actitudes igualmente estereotipadas frente a ellas: sentirse perseguidas, victimizadas, injustamente comprendidas o devaluadas, o bien intentar la "conversión" de las personas a la causa del género.

Experiencias exitosas de la inclusión del género en la educación -aunque con tareas aún pendientes-, se han dado en Argentina, Paraguay y Uruguay y para ello han utilizado diversas estrategias (Cortina y Stromquist, 2001).

En Argentina, el programa se incluyó con el nombre de "Igualdad de Oportunidades", y en Paraguay los conceptos de equidad de género fueron incorporados como "Educación Familiar" y así no despertar las reacciones a las que está expuesto el concepto de género.

Lo anterior, sin embargo, es considerado por teóricas de la educación y el género como un retroceso en los avances alcanzados, pues significa invisibilizar lo que tanto ha costado visibilizar.

Según mi opinión, estas estrategias son solo eso, estrategias para conquistar y validar espacios en la educación y así poder trabajar para alcanzar el objetivo político de la superación de las asimetrías. Las considero pertinentes, pues de ninguna manera significan el abandono de la vindicaciones de género. Es preciso reconocer, sin embargo, que este punto suscita posiciones a favor y en contra acerca de su eficacia ${ }^{6}$.

\section{¿Cómo se capacita?}

Los espacios que capacitan no se deben promover como los expertos, pues las experiencias vivencias y conocimientos del sector docente constituyen un fuerte insumo para el análisis de las relaciones sexistas. La división entre conocimiento "novato" y 
conocimiento "experto", por ende, debe desaparecer y promover más bien que el mismo profesorado participe de investigaciones y debates sobre las expresiones sexistas en los centros educativos donde laboran. Investigaciones sobre el lenguaje, los textos y los materiales que utilizan, la distribución y uso del espacio y la organización escolar son solo unos de los muchos temas que el sector docente podría investigar.

Con respecto a la formación inicial, indiscutiblemente serían las facultades de educación las responsables de atender este llamado y fundamentalmente los formadores y las formadoras de educadores y educadoras, quienes a su vez, deberían también ser involucradas e involucrados en un proceso de capacitación.

La coordinación con los gremios, con las oficinas de la mujer de los espacios ministeriales constituye un buen inicio para llevar a cabo la capacitación en el personal de servicio (formación continua).

Hay que advertir que la incorporación de un componente de género en la educación tiende a darse por medio de la educación continua o en programas de especialización y no en los programas iniciales.

En estos últimos no encontramos ningún esfuerzo sistemático de formación o introducción de una perspectiva de equidad de género. Es muy probable que ello sea producto de las tradiciones de formación docente prevalecientes en las facultades de educación -y que además podrían explicar sus reticencias para la inclusión del género-. Pese a ello, el reconocimiento de las contradicciones internas de estas facultades es también una tarea impostergable si se quiere entrar en estos espacios.

Por ejemplo, en la formación del profesorado en segunda enseñanza, se presenta una tensión entre formación general o pedagógica y la formación especializada. Esta disputa aun no está saldada y para trabajar con estos grupos hay que tener, al menos, conocimiento de qué está ocurriendo y las formas en que se enfrentan las contradicciones suscitadas por esta tensión.

Para finalizar, quiero hacer énfasis en la necesidad de iniciar la capacitación docente, aunque sea en aspectos muy puntuales. Para ello es necesario que exista consenso del mayor número de instancias, pues consensuar sobre una área de atención provoca movilización, mientras que los intentos aislados provocan desgaste antes de que aparezcan los frutos.

\section{Notas}

1. El biologismo anatómicodefiende la tesis de que el sexo anatómico determina diferencias en los comportamientos, en las características de personalidad y en las aptitudes de mujeres y de hombres. (Para ampliar, véase Sullerot, Elliot. El hecho femenino: ¿qué es ser mujer? Barcelona: Argos Vergara. 1979.

2. Los estudios de la mujer se han abocado a encontrar un equivalente en español del verbo empower y del sutantivo empowerment. Las revisiones realizadas señalan que no hay nada inmanente en estos términos. En español significan "dar poder" y "conceder a alguien el ejercicio del poder” (León, 1997).

3. De las personas que denuncian en el Poder Judicial $89,6 \%$ son mujeres y $86,5 \%$ de los denunciados son sus compañeros o excompañeros. En el caso de Rompamos el Silencio, de las llamadas que señalaron violencia sexual, 98\%, eran mujeres las víctimas de la agresión y en igual porcentaje eran hombres los agresores.

4. En toda la región de América Latina y el Caribe existe una correlación negativa entre el número de mujeres que ocupan puestos de jerarquía en el ámbito docente y administrativo y el número de mujeres que trabajan en educación. Asimismo conforme aumenta el nivel educativo, desciende el número de mujeres. En educación preescolar, según la especificidad de cada país, las mujeres representan entre $99 \%$ y $88 \%$ del profesorado mientras que en educación superior entre $38 \%$ y 15\% (Facultad Latinoamericana de Ciencias Sociales, 1995). 
5. Un ejemplo de estos programas es la Secretaría Permanente de la Mujer de la Asociación de Profesores de Segunda Enseñanza (APSE).

6. En octubre del 2001 se celebró en México la Primera Reunión Latinoamericana: Feminismos y Educación. La inclusión de este aspecto concitó los intereses de algunas de la participantes y no se logró un consenso al respecto. Mi posición en esta reunión es la que expreso en el presente escrito.

\section{Referencias bibliográficas}

Araya, Sandra. La equidad de género desde la representación social de los formadores y las formadoras del profesorado de segunda enseñanza. San Pedro, Universidad de Costa Rica (Tesis doctoral). 2001.

Bonder, Gloria. La equidad de género en las políticas educativas: Lecciones de la experiencia. Ponencia presentada en la Reunión Latinoamericana: Feminismos y Educación. México: Programa Universitario de Estudios de Género. 2001.

Carr, Wilfred. Una teoría para la educación. Hacia una investigación educativa crítica. Madrid, España: Morata. 1996.

Connell, Robert. Comentario sobre "Confounding Gender" de Hawkesworth. Debate Feminista, 20 (10) 70-75. México. 1999.

Connell, Robert. The State, Gender and Sexual Politics: Theory and Appraissal. En Davis, K., Leijenaar, M., Oldersma, J. (ed). The Gender of Power. London: Sage. 1991.

Cortina Regina, Stromquist Nelly. Promoviendo la educación de mujeres y niñas en América Latina. México: Editorial Pax. 2001.
De Barbieri, Teresita. Certezas y Malos Entendidos sobre la Categoría Género. En Guzmán, Laura, Pacheco, Gilda. Estudios Básicos de Derechos Humanos IV. San José, Costa Rica: Instituto Interamericano de Derechos Humanos.1996.

Estado de la Nación en Desarrollo Humano Sostenible. Sétimo Informe. San José, Costa Rica: Proyecto Estado de la Nación. 2002.

Facultad Latinoamericana de Ciencias Sociales. Mujeres latinoamericanas en cifras. Tomo comparativo. Santiago, Chile: Instituto de la MujerFLACSO. 1995.

Fuller, Norma. Reflexiones sobre el machismo en América Latina. En Valdés, T., Olavaria, J. (ed.) Masculinidades y equidad de género en América Latina. Santiago, Chile: FLACSO-Chile. 1998.

González, Mirta. Sexismo y educación escolar en Costa Rica. Madrid, España, Universidad Autónoma de Madrid (Tesis doctoral). 1987.

Guzmán, Laura. Informe de Consultoría. Sistematización y lineamientos para una propuesta teórico-metodológica de trabajo con mujeres adolescentes y jóvenes con perspectiva de género. San José, Costa Rica: Programa Mujeres Adolescentes, Unión Europea ALA 92/46. 1999.

Hawkesworth, Mary. Respuesta a McKenna y Kessler, Smith, Scott y Connell: interrogar el género. Debate Feminista, 20 (10) 76-83. México. 1999 .

Lagarde, Marcela. El amor femenino. En Instituto Interamericano de Derechos 
Humanos. Antología Género y Derechos Humanos. San José, Costa Rica: IIDH. 1994.

Lamas, Marta. Género, diferencias de sexo y diferencia sexual. Debate Feminista, 20 (10) 84-106. México. 1999.

León, Magdalena. El empoderamiento en la teoría y la práctica del feminismo. En León, Magdalena (comp.). Poder y empoderamiento de las mujeres, Bogotá, Colombia: Tercer Mundo S. A, 1997.

McKenna, Wendy, Kessler, Susan. Comentarios y respuestas a Confounding Gender de Hawkesworth ¿Quién necesita la teoría del género? Debate Feminista, 20 (10) 49-53. México. 1999.

Morgade, Graciela. Aprender a ser mujer. Aprender a ser varón. Relaciones de género y educación. Esbozo de un programa de acción. Buenos Aires- México: Novedades Educativas. 2001.

Mosconi, Nicole. Diferencia de sexos y relación con el saber. Buenos Aires,
Argentina: Novedades Educativas. 1998.

Ramos Pilar. Segregación por género en la estructura ocupacional de Costa Rica. San José, Costa Rica: Proyecto Estado de la Nación. 2002.

Scott, Joan. Comentario sobre "Confounding Gender" de Hawkesworth. Debate Feminista, 20 (10). 65-69. México. 1999.

Smith, Steven. Comentario sobre "Confounding Gender" de Hawkesworth. Debate Feminista, 20 (10) 55-63. México. 1999.

Sullerot, Elliot. El hecho femenino: ¿qué es ser mujer? Barcelona: Argos Vergara. 1979.

Unión Europea. Estrategias para el sistema de educación en el proceso de formación e incorporación productiva de las mujeres adolescentes. San José, Costa Rica: CEGESTI. 1999.

Sandra Araya Umaña Investigadora del IIMEC y Docente del Programa de Posgrado en Trabajo Social Universidad de Costa Rica 